\title{
PERAWATAN DINAMO MOTOR STARTER PADA MOBIL
}

Reza Fahlevi ${ }^{1}$, Syahrival Ghozali ${ }^{2}$, Rafly Aulia $\mathbf{R}^{3}$, Moh. Thoriqur ${ }^{4}$

Universitas Muhammadiyah jember, Prodi Teknik Mesin

\section{Abstrack}

Saat ini kendaraan baik itu mobil maupun sepeda motor kebanyakan menggunakan starter tipe elektrik, terkadang sering kita menjumpai pada beberapa kendaraan tertentu dimana dynamo starter itu tidak bekerja semana mestinya,maka dari itu diperlukan adanya pemeriksaan atau perawatan pada komponen penting untuk memutar poros engkol

\section{Abstrack}

Currently vehicles both cars and motorcycles mostly use electric type staters, sometimes we often find in certain vehicles where dynamo starter does not work as it should, therefore there is a need for inspection or maintenance on important components to rotate the crankshaft.

\section{A. TUJUAN}

1. Mahasiswa diharapkan dapat memahami prinsip sistem kerja motor starter pada kendaraan roda empat.

2. Mahasiswa dapat mengidentifikasi dan memperbaiki masalah kerusakan pada motor starter.

3. Sebagai penambah wawasan kepada para pembaca.

\section{B. LANDASAN TEORI}

Memasuki era saat ini inovasi yang di dapat di bidang otomotif saat ini semakin banyak pemakaian dan teknologi 
yang terbaru. Di masa-masa saat ini kendaraan sudah memakai berbagai sistem yang maju, salah satunya dari sistem itu yaitu sistem motor starter [1].pengertian sistem starter. Sistem starter yaitu merupakan sistem yang berfungsi menghasilkan tenaga gerak untuk memutar poros engkol agar mesin dapat hidup.[2].Torsi yang di butuhkan untuk memutar poros engkol motor bensin 4-6 silinder dengan kapasitas silinder 1000 sampai 2000 cc mencapai $6 \mathrm{kgm}$ dengan kecepatan putar poros engkol antara 60-90 rpm Bila torsi yang dihasilkan kurang maka putran motor menjadi rendah atau tidak dapat berputar sama sekali, sehingga proses pemasukan maupun kompresi tidak memenuhi syarat untuk proses pembakaran, dengan demikian bila momen yang di hasilkan motor starter kurang maka motor sulit hidup Sistem starter mekanik banyak digunakan untuk motor dengan kapasitas silinder kecil seperti motor penggerak kompresor dan sepeda motor.Menghidupkan dengan sistem starter mekanik memerlukan tenaga manusia yang besar dan tidak praktis dalam oprasionalnya Sehingga sistem starter mekanik sudah jarang digunakan. Pada saat ini hampir semua mesin menggunakan starter elektrik, karena sistem starter elektrik lebih ringan dan mudah oprasionalnya Pengendara cukup memutar kunci kontak atau menekan tombol stater untuk menghidupkan mesin.[3]. ACG (Alternating Current Generator) yaitu sistem yang menghasilkan arus listrik bolak-balik (AC) dan Starter 
adalah alat untuk memulai kerja suatu alat lain. Pada mesin Mattrix Gasoline Engine CX200 masih menggunakan starter manual yaitu dengan menarik tali yang diikatkan pada suatu sistem kopling untuk memutarkan poros engkol

[4]. Motor bakar torak bensin merupakan mesin pembangkit tenaga yang mengubah bahan bakar bensin menjadi tenaga panas dan akhirnya menjadi tenaga mekanik. Pada saat awal sepeda motor mulai diproduksi sistem pengapian pada motor bensin menggunakan sistem pengapian konvensional (platina). Sistem pengapian sepeda motor sekarang kebanyakan menggunakan system pengapian CDI (Capacitor Discharge Ignation) yang memiliki karakteristik lebih baik di bandingkan dengan system pengapian konvensional.Sistem pengapian merupakan sistem yang sangat penting pada speda motor. Metode eksperimental adalah metode yang digunakan untuk menguji pengaruh dari suatu perlakuan atau desain baru dengan cara membandingkan desain tersebut dengan desain tanpa perlakuan sebagai kontrol atau pembanding.melakukan pengambilanm[5]. Rangkaian star delta motor listrik adalah posting selanjutnya setelah beberapa waktu yang lalu saya telah membahas tentang "gambar hubungan star delta motor listrik 3 fasa" rasanya tidak sah kalau tidak mengaplikasikannya dan membuat rangkaian kontrolnya. Berbicara tentang rangkaian star delta motor listrik, apakah semua motor listrik 3 fasa harus di jalankan sesuai judul posting kita kali ini ?. Ternyata 
tidak, namun yang sangat menentukan apakah motor listrik yang kita miliki akan di pasang dengan rangkaian star delta atau star saja atau delta saja adalah berkaitan dengan sumber listrik yang tersedia dan keterangan (Name Plate) yang dimiliki oleh motor listrik tersebut. Sebenarnya apa sih tujuan dari rangkaian star delta pada motor listrik 3 fasa ? tidak lain adalah untuk mengurangi nilai arus start yang besarnya sekitar $2-5$ kali arus nominal motor listrik. Berikut ini saya beri gambaran dari beberapa name plate motor listrik 3 fasa[6].Cara Pemeriksaan Motor Starter - Motor starter adalah salah satu komponen mobil yang memiliki peranan penting dalam kaitannya dengan proses starting (menghidupkan kendaraan diawal). Saking vitalnya fungsi dari motor starter, jika terjadi kerusakan pada komponen ini mungkin kendaraan anda tidak dapat dihidupkan dengan praktis.

Kita tahu dalam proses menghidupkan mesin, mesin membutuhkan tenaga eksternal untuk menggerakan fywheel

Karena motor starter ini merupakan komponen yang selalu dipakai ketika kita menghidupkan kendaraan, maka lambat laut komponen ini akan mengalami penurunan performa, bahkan dalam beberapa kasus sering terjadi kerusakan. [7]. Dinamo stater pada mobil mempunyai fungsi untuk memutar mesin pertama kali. Nantinya, dinamo stater akan mengubah energi listrik menjadi energi gerak. Dimana pengubahan energi ini digunakan untuk memutar crankshaft mesin, atau poros mesin melalui fly wheel, atau 
disebut juga roda gila. Perawatan dinamo stater mobil perlu diperlakukan khusus. [8] Agar motor starter selalu bekerja dengan baik dan selalu siap pakai, maka perlu dilakukan perawatan pada sistem starter ini.. adalah komponen yang berfungsi untuk menghidupkan atau menjalankan sebuah mesin. Pada mesin kendaraan sendiri, sistem starter berfungsi untuk mengubah arus listrik yang terdapat pada aki menjadi energi mekanik. Energi mekanik ini akan dapat membuat mesin dari kendaraan tersebut dapat bergerak dan berjalan[9]. Pemeriksaan komponen- komponen motor starter pada Toyota Kijang Seri 5K dilakukan dengan cara visual dan pengukuran sesuai dengan spesifikasi yang ditentukan. Pengujian arus motor starter dilakukan dengan pengujian motor starter tanpa beban, ada beban saat kompresi los, ada beban saat kompresi aktif dengan menggunakan Ampermeter. .[10]. Saat kunci kontak berada di posisi "ON" relay utama atau main relay akan terhubung, menyebabkan arus dari baterai mengalir ke semua sistem kelistrikan mobil.

Saat kunci kontak diputar pada posisi "ST", relay starter switch akan terhubung sehingga arus akan mengalir dari baterai ke terminal 50 pada starter clutch.[11]. Pada kendaraan mobil hanya memakai starter tipe elektrik. Pada motor starter elektrik terdapat beberapa komponen, komponen-komponen dari motor starter terdiri dari yoke and pole, kumparan medan (field coil), armature, pinion gear, magnetic 
switch, brush, tuas pendorong, armature brake, kopling geser dan lain-lain.

Agar motor starter dapat bekerja dengan baik maka pemeriksaan kondisi motor starter perlu untuk dilakukan Pemeriksaan.[12]. Komponen tersebut apabila salah satu rusak atau tidak berfungsi dengan normal akan mengakibatkan terganggu atau bahkan tidak berfungsinya sistem motor starter pada mobil atau motor. Sehingga perlunya pemeriksaan dan perawatan pada motor starter agar kerja dari sistem secara optimal.[13]. Prinsip kerja Rangkaian star delta sederhana sekali yaitu Ketika tombol start di tekan sesaat maka kondisi star akan aktif. Sesaat kemudian kondisi star akan mati bergantian dengan kondisi delta yang akan menyala. Perpindahan antara kondisi star ke delta di atur waktunya secara otomatis oleh timer, yaaa sekitar 3 detik gitu. Sedangkan tombol stop berfungsi untuk memutus aliran listrik keseluruh rangkaian.[14].Motor matic Honda keluaran terbaru sekarang sudah menganut teknologi Alternating Current Generator (ACG) starter.

Starter tipe ini tidak lagi membutuhkan dinamo starter konvensional untuk memutar kruk as dan

menciptakan pembakaran awal. Pada ACG Starter tidak adalagi dinamo starter konvensional dan mekanisme gigi penggeraknya, makanya motor matic Honda sekarang bersuara halus saat tombol starter dipencet. Perangkat starter yang sekaligus menjadi altenator ini sebenarnya sudah diadopsi pertama kali pada Honda PCX 125 Cara kerja ACG starter 
sebenarnya sama seperti prinsip kerja alternator pada umumnya. Hanya bedanya, pada awal menekan tombol starter, putaran magnet digunakan untuk menghidupkan mesin. Alternator pada Vario Techno 125 ini memiliki 12 kutub magnet permanen yang terdapat di fly wheel. Juga memiliki 18 kumparan yang memiliki kutub magnet remanen atau magnet tidak tetap.[15]. Teknologi ACG Starter (Alternating Current Generator) menjadi keunggulan dari Astra Honda Motor (AHM) untuk motor-motor terbarunya. Fitur ACG Starter ini bisa dibilang yang menghilangkan suara keras pada saat Anda menyarter motor. Berikut ini kami akan kupas tuntas teknologi ACG Starter yang dimiliki motor Honda. Sebelum keunggulan dari fitur ACG Starter ini. Mengurangi getaran dan bunyi pada motor Anda saat menyalakan mesin motor Mengurangi konsumsi BBM karena terdapat sistem decompression yang mempermudah kerja piston Dapat mengisi aki secara otomatis

Menjamin perawatan motor karena tidak menggunakan brus yang biasanya hanya terdapat pada dynamo biasa. Pengertian

\section{ALAT DAN BAHAN}

Alat dan Bahan yang perlu dipersiapkan,meliputi sebagai berikut:
1. Kunci T
2. Obeng [+] dan [-] 
3. Stemped

4. Avometer

5. Kunci Pas dan Kunci Ring

6. Kabel Jumper

7. Dinamo Starter

8. Aki

9. Bak penampung komponen

\section{PROSEDUR}

Hal yang perlu dilakukan dalam perawatan motor stater, adalah sebagai berikut:

1. Pemeriksaan Pull in coil

Pada pemeriksaan pull in coil ini AVO harus menunjukan adanya kontinuitas. Untuk melakukan pemeriksaan puul in coil lakukan Langkah berikut:

- Gunakan AVO meter

- PUtar selector pada posisi OHM

- Tempatkan probe pada terminal 50 dan terminal C

2. Pemeriksaan Hold in coil Untuk melakukan pemeriksaan Hold in coil lakukan Langkah sebagai berikut:

- Gunakan AVO meter

- Putar selector pada posisi OHM

- Tempatkan probe pada terminal 50 dan body magnetic switch

3. Pemeriksaan contact plate 
Untuk melakukan pemeriksaan contact plate pada magnetic switch lakukan Langkah sebagai berikut:

- Gunakan AVO meter

- Putar selector pada posisi OHM

- Tempatkan probe pada terminal 30 dan terminal $\mathrm{C}$ kemudian tekan pluyer

4. Pemeriksaan diameter komutator Untuk melakukan pemeriksaan lakukan Langkah sebagai berikut:

- Gunakan vernier calliper

- Perhatikan posisi alat ukur dan objek ukur

- Lakukan pembacaan hasil ukuran

Bandingkan hasil pengukuran dengan spesifikasi pada buku manual kendaraan tersebut. Jika sudah mencapai batas limit maka harus diganti

5. Pemeriksaan hubungan singkat armature dengan massa Untuk melakukan pemeriksaan hubungan singkat armature dengan massa,lakukan Langkah sebagai berikut:

- Gunakan AVO meter

- Putar selector pada posisi OHM

- Tempatkan satu probe pada segmen komutator dan yang lain pada armature core(tidak ada kontinuitas/hubungan) 
6. Pemeriksaan hubungan antar segmen (komutator) Untuk melakukan pemeriksaan antar segmen (komutator) lakukan Langkah sebagai berikut:

- Gunakan AVO meter

- Putar selector pada posisi OHM

- Tempatkan kedua probe pada masing masing segmen

7. Pemeriksaan Panjang brush Untuk melakukan pemeriksaan Panjang brush/sikat, lakukan langkah berikut:

- Gunakan vernier caliper/jangka sorong

- Untuk melakukan pengukuran Panjang brush tempatkan pada posisi yang tepat kemudian lakukan pembacaan hasil pengukuran

Ganti brush bila brush duah melewati batas limit yang diperbolehkan daengan melihat buku manual kendaraan.

8. Pemeriksaan fild coil

Pemeriksaan fild coil berarti sedang memeriksa kumparan medan dari kemungkinan putus. Untuk melkukan pemeriksaan fild coil lakukan Langkah sebagai berikut:

- Gunakan AVO meter

- Putar selector pada posisi OHM 
- Temptkan probe pada brush yang bersebrangan dan pada kondisi ini harus terdapat kontinuitas

9. Pemeriksaan kumparan medan terhadap kemungkinan hubungan singkat dengan massa Lakukan hal berikut:

- Gunakan AVO meter

- Putar selector pada posisi OHM

- Tempatkan salah satu probe pada brush dan satunya lagi pada body yoke

10. Pemeriksaan starter clutch

Pemeriksaan starter clutch dengan cara putar starter clutch searah jarum jam maka pinion gear akan dapat berputar bebas. Kemudian putar starter clutch berlawanan arah jarum jam dan pinion gear akan terkunci

\section{E. HASIL}

Hasil dari kegiatan tersebut (perawatan dinamo starter) adalah:

1. Dinamo starter Kembali bekerja dengan semestinya

2. Bila dinamo starter kembali normal maka menghidupkan mesin akan terasa lebih mudah tanpa harus menggunakan kick starter

\section{F. KESIMPULAN}

Pada penulisan diatas juga akan menyampaikan tentang perawatan dinamo stater, pada saat melakukan Tugas Akhir: 
1. Setelah melakukan over haul yang di sebut dengan perwatan dalam pada dinamo starter penulis dapat mengidentifikasi komponenkomponen pada dinamo motor starter yaitu: baterai,ignition switch (kunci kontak), relay,dan komponen motor starter yang meliputi: armature, field coil,magnetic switch, pinion gear, drive lever, dan brush. Yang kenyataan di lapangan komponen pada dinamo motor starter yang penulis analisa masih dalam batas standar, dan tidak perlu melakukan penggantian dalam komponen dalam dinamo motor stater ketika tidak ada yang rusak maupun hal lainnya.

2. Kerusakan yang sering terjadi pada dinamo motor setarter yang sering diakibatkan karena adanya kurang perawatan atau perhatian dari pengguna kendaraan tersebut yang akan pentingnya perawatan pada dinamo motor starter, selain hal di atas kerusakan yang sering terjadi pada dinamo motor starter yaitu dari gigi pinion dan brush.

3. Setelah penulisan melakukan pengetesan atau pengujian pada dinamo motor starter yang penulis analisa, dan ternyata dinamo motor starter masih dapat berfungsi secara baik atau tidak dan tidak ada gangguan yang terjadi pada dinamo motor stater. 


\section{G. DAFTAR PUSTAKA}

[1] Suzuki, "Mengenal Fungsi dan Komponen Motor Starter," pp. 1-2, 2022.

[2] Y. Khoiri, N. A. Mufarida, and K. Kosjoko, "Pengaruh Penggunaan Variasi Bahan Bakar Pertamax, Pertalite Dan Premium Terhadap Performa Mesin Motor Injection 115 Cc Tahun 2013," J-Proteksion, vol. 3, no. 2, p. 29, 2019, doi: 10.32528/jp.v3i2.2249.

[3] F. Majedi, F. Susanto, and A. Hardiyanto, "Penerapan Sistem Alternating Current Generator (Acg) Pada Motor Bensin mattrix Gasoline Engine Cx200," J. Teknol. Terpadu, vol. 6, no. 1, pp. 77-81, 2018.

[4] A. Putra, Ikhfan Tri Wahyulianto.Mufarida, S.T., M.T.2, Nely Ana.Finali, S.T., M.T.3, "PERBANDINGAN CDI STANDAR DAN CDI VARIASI TERHADAP PERFORMA MOTOR 4 TAK 100 CC," vol. 2, no. 2, pp. 17-22, 2018.

[5] Juan, "Komponen-Komponen Motor Starter dan Fungsinya," vol. L, pp. 1-12.

[6] I. Panggalo, R. Y. Dillak, and F. Da Silva, "Rancang Bangun Sistem Starter Sepeda Motor Menggunakan Smartphone Berbasis Mikrokontroller," J. IIm. Flash, vol. 4, no. 1, p. 17, 2018, doi: 10.32511/jiflash.v4i1.206.

[7] Lia, "Perawatan Dinamo Stater Mobil Agar Awet.," pp. 110.

[8] Daihatsu, "Mengenal Apa Itu Sistem Starter Mobil Beserta Komponennya," pp. 1-4, 2021. 
[9] setyo hadi Utomo, "Mekanisme Dan Troubleshooting Serta Pengujian Arus Motor Starter Pada Toyota Kijang Seri 5K," 2007.

[10] agus wakit Hasim, "IDENTIFIKASI SISTEM STATER TOYOTA KIJANG INOVA," Nhk技研, vol. 151, pp. 10-17, 2015, doi: 10.1145/3132847.3132886.

[11] S. Agus, "Proses Memperbaiki Gangguan Motor Starter pada Sepeda Motor Honda Astrea Grand Tahun 1997 Suprihadi Agus," 2012.

[12] A. Setiawan, T. Mesin, and P. Raflesia, "Analisa Kerusakan Dan Perbaikan Sistem Starter Pada Sepeda Motor Supra X 2002," vol. 7, no. 2, pp. 43-50, 2021.

[13] O. A. Akhdan, "Oil Type Transformer Supplier," pp. 1-12.

[14] F. Majedi, F. Susanto, and A. Hardiyanto, "Penerapan Sistem Alternating Current Generator (Acg) Pada Motor Bensin.," J. Teknol. Terpadu, vol. 6, no. 1, pp. 77-81, 2018.

[15] M. Astra, "Pengertian ACG Starter," 2019. 